\title{
Leadership Roles and Motivation Factors Leading to Occupational Burnout amongst Staff, including Nurses, Working in the Public Health Field
}

\author{
Aikaterini Frantzana* and Marianna Charalambous \\ Aikaterini Frantzana, European University of Cyprus, Department of Health Sciences, Cyprus. \\ *Corresponding author: Aikaterini Frantzana, European University of Cyprus, Department of Health Sciences, Cyprus, George \\ Papanikolaou General Hospital of Thessaloniki, Greece.
}

To Cite This Article: Aikaterini Frantzana. Leadership Roles and Motivation Factors Leading to Occupational Burnout amongst Staff, including Nurses, Working in the Public Health Field . Am J Biomed Sci \& Res. 2019 - 3(3). AJBSR.MS.ID.000666. DOI: 10.34297/AJBSR.2019.03.000666

Received: May 07, 2019 | Published: June 07, 2019

\begin{abstract}
Introduction: Occupational Burnout consists a modern problem in Public Health workplaces. The present paper was conducted in the context of the analysis of the leadership and instigation factors as well as the way they can affect the Occupational Burnout amongst staff working in the public health field including nurses.
\end{abstract}

Purpose: The reasons for choosing the ideal leadership in the Path Goal Theory are put forward and a realistic incentive framework is presented so as Occupational Burnout to be reduced in Greek public hospitals.

Methodology: This paper includes a scrutinized search of review and research studies conducted internationally as well as in Greece while they refer to the Occupational Burnout Syndrome.

Results: The complex and stressful field of Public Health requires a combination of rapid and intense work rates that lead to the onset of the Occupational burnout Syndrome. Significant staff shortages, debilitating circular working hours, imprecise definition of tasks, the absence of economic and social incentives, along with the need of cooperation with different characters and different specialties necessitate not only the proper management of materials and human resources but also the implementation of policy incentives for employees' motivation. The leader shares the employees' needs for recognition as personalities, satisfaction of their personal aspirations, professional development and training by designing appropriate training and informational schemes. This motivation must include the satisfaction of individuals' needs within a rational work schedule.

Conclusions: Timely diagnosis of Occupational Burnout, empowerment, counseling and support of the staff in Public Health sector, including nurses, could help address the Burnout Syndrome. The effective leader must utilize the appropriate motivation and stimulation for his staff.

Keywords: Occupational burnout; Hospital leadership; Nursing; Motivation; Motivation theories; Instigation; Leadership

\section{Introduction}

The workplace and the working conditions prevailing in it have a significant effect on employees' physical and mental health as they devote about one third of their day to them. In the field of Health, the complex and stressful profession of a modern heath care specialist, including nurses, requires rapid and intense work rates which combined with increased workload, tension, wage reduction, minimizing opportunities for personal development, lack of supportive climate between colleagues and superiors and the personal characteristics of each employee lead to the occurrence of Occupational Burnout [1,2].
The first mention of the Occupational Burnout Syndrome, known as Burnout, was made by Freudenberger in 1974. The etymology of the word is "progressively drawn from the inner to the point of charring" [3,4]. According to the definition of Maslach [5] in 1982 as Burnout Syndrome is characterized: "The loss of interest in people with whom one works; it also includes physical exhaustion and it is characterized by emotional exhaustion where the professional no longer has any positive feelings of sympathy or respect for clients or patients" [5]. 
Today, Occupational Burnout consists the modern disease of the 21st Century for employees while the ideal way to prevent and reduce its appearance is to recognize symptoms immediately in order to avoid:

a) emotional exhaustion

b) depersonalization

c) sensation of reduced personal achievements [6]

According to OECD data in Greece: [7]

I. There are 3.6 nurses per 1,000 inhabitants when the average in the EU is 9.1 nurses per 1,000 inhabitants, with Switzerland rising to 17.4 nurses per 1,000 [8].

II. There are 6.3 doctors per 1,000 inhabitants, when the average in the EU is 3.3 doctors per 1,000 inhabitants [8].

III. The proportion of nurses-doctors is 0.6 to 1 with the average in the member countries being 3 to 1 and in some countries like Denmark and Finland the correspondence is 4.5 nurses per doctor [9].

IV. The proportion of nurses-patients in hospitals is 1 in 20 in the morning and afternoon shift, while in the night shift it is 1 to 40 with a quality care of 10 minutes per patient per shift. The International Board of Nurses says a nurse should take care of 4 patients, thus maintaining safety levels and reducing mortality due to underweight, which could otherwise reach 6\% [10].

The average Greek employee works about 2,035 hours a year; in the USA the average work time is 1,783 hours per year while the Germans work only 1,363 hours [11].

Occupational Burnout is the result of long-term accumulation of work-related stress. It affects the worker in various ways: [12]

I. Physical symptoms: chronic fatigue, atony.

II. Behavioral changes: conflicts with colleagues, irritability.

III. Interpersonal relationships: isolation, social alienation.

IV. Psychological effects: anger, depression.

V. Psychosomatic effects: sudden sweating, disorientation.

VI. At work: lack of interest, low morale.

Considering all the above, it can be easily understood: [13]

I. It is vital the Presidential Decree on the basis of which the permanent vacant positions for employment are calculated be modified and readjusted immediately in order to increase the number of nurses per each patient.

II. According to existing conditions in hospitals, people holding positions of authority do not only perform organizational tasks, but they also take on the role of leader influencing the appearance of the Occupational Burnout Syndrome to a significant extent.

The type of leader is the one that will stimulate and define the kind of communication, mutual respect, cooperation and the formation of a healthy environment, eliminating stress, pressure and conflicts [14]. Regarding the factors having an impact on the hygiene and safety of working surroundings, they include the work nature, working conditions and employee's personal outlook towards hygiene-safety, which may vary from intense interest to complete apathy $[15,16]$.

The purpose of this review study is to present and elaborate a realistic incentive framework aiming at reducing Occupational Burnout in Greek public hospitals, focusing on applying the right incentive method and choosing the effective leader for each case. The methodology used includes the search of review and research studies conducted at an international and Greek level while they referred to Occupational Burnout. The criterion of exclusion of the articles was the language, except for Greek and English.

\section{The Leadership Role and Motivation of Nurses}

Employment is the means of securing financial resources for many employees to meet the needs of consumer society. Furthermore, it is the place where workers seek recognition, honor, personal development and achievement of their goals so as to maintain healthy physical and mental health inside and outside their workplace [17]. The extent to which these needs are met is closely related to the nurses' satisfaction from their work, which is reflected in the efficiency, effectiveness and quality of the health services provided [13].

Significant staff shortages, debilitating circular hours, imprecise definition of tasks, the absence of economic and social incentives, and cooperation with different characters and different specialties necessitate the proper management of materials, equipment and human resources, as well as the implementation of policy incentives for the employees' motivation [18]. In nursing, staff motivation is aimed at improving the quality of patients' care, and at the same time, developing the efficiency and effectiveness of healthcare. The stimulation must include the satisfaction of individual needs within a rational work program [19].

Luthans was the first to develop the theory of motives; he also classified them into three categories: [20]

I. Primary motives that are biological necessities such as hunger and thirst.

II. General motives which are not biological but inherent, such as satisfaction, curiosity, manipulation, affection and love.

III. Secondary motives derive from socialization. They are learnt and acquired over time such as safety, success, prestige and power.

Since then, various theories referring to motivation have been developed, all of which are aimed at discovering employees' needs and providing them with the proper incentives to activate them, as well as choosing the appropriate type of leadership that fits in any case [21]. The incentive practice is based on the worker's recognition and offering him financial (e.g. productivity bonus) or non-financial rewards (e.g. continuous employee development) (Figure 1) The following figure depicts the motivation process (Figure 2). In a 
Nursing Department, the head of the administration is the Nurse Manager whose role is very important, and he is called upon to have the necessary qualifications and skills referring to his personality and leadership characteristics in order to be able to fulfill his duties successfully. He is called to become a leader and apply the appropriate leadership style for each case while maintaining the balance of satisfaction between nurses and patients [14].

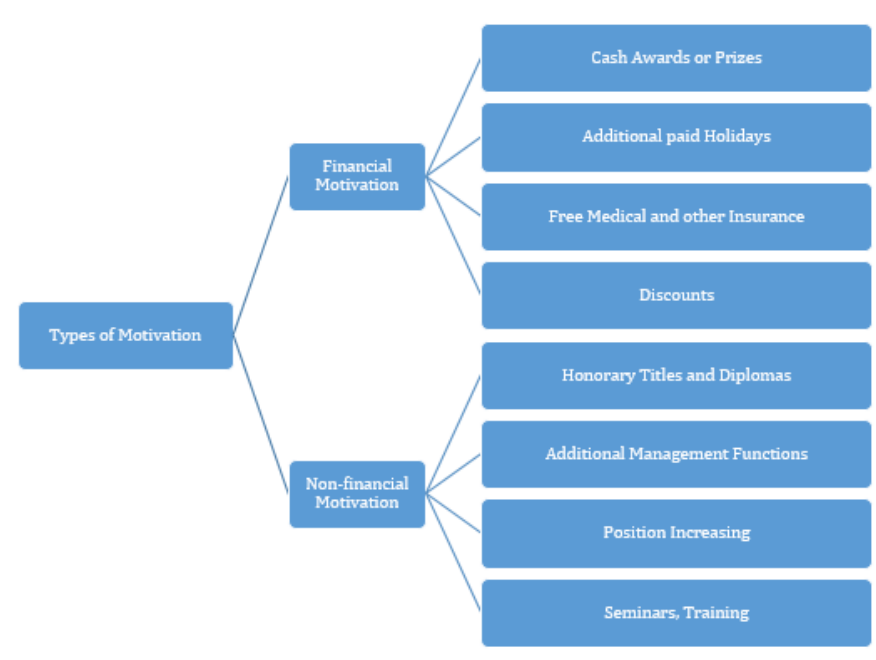

Figure 1: Motivation Types.

Figure 2: The Motivation Process.

An exemplary leader must be distinguished for his emotional intelligence, abilities, personality, prestige, creativity and intelligence [18]. Applying such motivation theories and the right means of communication is the cornerstone of Health Leaders' success [22]. According to Patrinos \& Anastasiou [10] leadership is "the influence, the art, or the process of influencing behavior, acts, activation and guidance of a formal or informal organization -a small or large group, in such a way that the group would be most willing to strive voluntary to achieve specific goals with the greatest possible efficiency [10].

The basic styles of leadership are three: [11]

I. The Authoritarian Leadership Style is exemplified when the leader reaches decisions on his own and he simply announces them.

II. The Democratic Leadership Style is exemplified when the leader takes into account the employees' needs and attitudes while trying to create a sense of responsibility and cooperation.
III. The Impoverished or Indifferent Leadership Style is exemplified when the leader does not assume his responsibilities and sets no goals reducing the interest of employees in their workplace.

Not only does Nursing Leadership aim at patients' safety and satisfaction but it is also called upon to make effective use of the imponderable human factor, while simultaneously contributing to satisfaction and further development. Employees with many abilities, skills and knowledge have been proven to perform less than the ones who have less ability but proper motivation by the appropriate leader [23].

\section{Path Goal Theory-Goals and Implementation}

Path Goal Theory was analyzed by House in the early 1970's. The theory describes the leader having no specific orientation but role. The theory asserts that the employees' performance depends on the degree of satisfaction of their expectations. Thus, the task of the leader is to implement them $[8,11]$ : 
a) Knowing the needs of his subordinates

b) Defining their duties

c) Motivating and influencing their behavior

d) Defining goals

e) Shaping the way for the goal implementation,

f) Removing the obstacles

The leader uses different but appropriate leadership patterns for each and every case like "pathways" to achieve his goals, always taking into account the characteristics of his employees and the duty [10].

\section{The styles of the Path Goal Theory are: [11]}

I. The Instrumental Style is applied in cases where duties are vague, to new employees and to ones whose performance is low, and they are not interested in the job. The leader determines what needs to be done, by whom, when and how, by defining the reward in order the goals to be achieved [6].

II. The Supportive Style is applied in cases where duties are defined, routine and unattractive. The relationship between the leader and the employee is friendly. Leaders apply this style to new employees or people with adaptive problems. The leader communicates with them, cares for their needs and supports them to participate gregariously in work tasks in order to fulfill the defined goals [12].

III. The Participative Style is applied in conditions where employees are stressed and afraid of future failure of goals. The leader discusses with employees while sharing their needs. He takes into account their views through the exchange of information before making a decision on any problems that arise in the organization and deviate from the goal [6].

IV. The Achievement Oriented Style is applied to the majority of employees and especially to the middle classes. The leader sets very hard goals and helps employees considerably by supporting them. He has great expectations of his employees' abilities for the fulfillment of difficult goals. The targets set should be achievable because otherwise workers will be disappointed [24].

Healthcare has undergone many reforms in recent years, resulting in reduction of funds, staff, employee and human resources. Additionally, there seems to be great increase in workload and a change as regards job fulfillment, resulting in occupational burnout of employees. All the aforementioned factors have an impact on the administration way performed by public hospitals [14].

Referring to the latter, it should be noted that in order to achieve the goals set by hospital managers concerning employees' satisfaction, besides motivation, the administration should also take the type of leadership that is appropriate for the case to be used into consideration, as the style of leadership will determine the type, mode, and form of incentive that will be applied to counteract occupational burnout [25].
As follows, the reasons for developing the supportive style would be analyzed which, according to the prevailing conditions, should be applied to public hospitals, contributing to the satisfaction of the employees' expectations and reducing occupational burnout rates $[10,11]$ :

I. The leader shares the needs of his / her employees for recognition as personalities, satisfaction of their personal aspirations, professional development and training by designing appropriate training and information programs [14].

II. He creates a favorable environment for their development and, through a climate of trust, support and mutual respect among them, cultivates cooperation and develops the coherence of the group. He implements some dialogue and active listening. At the same time, he empowers the staff and helps them develop problem-solving skills. A friendly and approachable leader inspires positive feelings and helps workers to get rid of unnecessary work stress [26].

III. The leader regulates the activities of the employees and the nursing department. He takes care of placing the appropriate employees in the appropriate positions according to their experience, knowledge and specialization. $\mathrm{He}$ is responsible for the sufficient number of department staff to cover all nursing needs and shifts, avoiding overloading tasks [17]. He is objective, impartial, and neutral while he treats each member of the staff in the same way without any hatred or prejudice. He implements the staff rotation plan helping his employees avoid occupational burnout. He is responsible for staffing the department by providing it with the necessary tools and equipment to enable his staff to fulfil their duties [27].

IV. The leader clearly defines the duties and responsibilities of each employee by clarifying the roles and goals, avoiding confusion [28]. He limits potential obstacles with the proper guidance and counseling aspiring his staff to achieve the desirable goals. Simultaneously, the leader announces staff rewards, which may involve moral rewards; for example, the nurse of the year or self-realization (assignment of specific tasks) [17]. Individual results are then checked, and the workload is classified. Then, a rotation of duties among employees follows so as routine to be avoided and more interest to be sparked [29].

\section{Occupational Burnout and Motives}

Scientists are engaged in motivation theories for more than a century trying to find out the motives that may affect work performance. According to the data of Basic Principles of Health Services Management, motivation theories are classified into two major categories: [30]

The theories referring to the motivation content:

i. Maslow's Hierarchy of Needs (Maslow, 1943).

ii. Herzberg's Two Factors Theory (Herzberg, 1959).

iii. Mc Clelland's Theory of Needs (Mc Clelland, 1953). 
The theories focusing on the motivation process:

i. Vroom's Expectancy Theory (Vroom, 1964).

ii. Adam's Equity Theory (Adams, 1965).

A realistic nursing motivation framework would be tried to be developed based on two of the above theories, Theory of Needs and Expectancy Theory, so as occupational burnout to be lessened [31].

\section{Theory of Needs}

a) The staff who have the need to achieve goals are selected or moved to interesting occupational positions where tasks are demanding and difficult as they usually work on their own. These individuals undertake duties with personal responsibility and are satisfied with the successful completion of their mission as long as there is positive feedback; in other words, direct confirmation of their effort and success by the

\section{Expectancy Theory}

leader [32].

b) Employees who have developed interpersonal skills are placed in groups where they enjoy a sense of acceptance and recognition. These people need mutual understanding and perform better when working with colleagues, thereby meeting their needs and have more chances of success [28].

c) The goal achievement lies behind the desire for power. The employees have a strong sense of control and influence on the behavior of others. Their leader assigns them tasks that require decision making and cover administrative and organizational positions [11].

The manager leader must recognize the particularities and personal characteristics of the employees according to the categories of motivation above to understand the extent to which they will be satisfied with the type of work they will be assigned [32].

Figure 3: Expectancy Theory.

The complete Expectancy Theory is shown in Figure 3. Each and every nurse chooses an action, according to his needs and abilities, due to motivation and expects his efforts to produce the appropriate performance and the result that will satisfy him $[17,33]$. The nurse acknowledges that the performance will be equal to his efforts and abilities, knowing in advance its rewards and benefits. The kind of rewards must satisfy his needs and be valuable for him concerning his productivity, but they must also be fair regarding other colleagues [34].

The leader before setting such an incentive must take into account the desires and the value of the reward placed on each employee. Such motivation would help nurses understand what the boss exactly expects from them and the reward they may receive if they successfully complete their working task each time. Rewards may be of positive nature and come from the working surroundings; for instance, pay rise, praise, and appraisal or derive from the employee himself such as recognition of his efforts or personal development [10,17].

Physical and mental exhaustion along with dissatisfaction experienced by nurses in the workplace results in their being prone to the emergence of Occupational burnout Syndrome [35]. Early recognition and prevention of the symptoms in combination with necessary knowledge, as well as employees" education regarding health promotion will prevent the commencement of this syndrome [36]. The recovery will be feasible if the health system establishes risk and safety limits in Greek hospitals and intervenes appropriately for the right leadership selection [15]. Moreover, the health system has to apply the appropriate incentives in each case.

\section{References}

1. Karaniadou A, Anagnostopoulos F, Teloni MK (2006) Demographic, labor and administrative factors that affect the exhaustion of doctors and nurses. 45(3): 391-403.

2. Lera M, Tachtsoglou K, Iliadis Ch, Frantzana A, Kourkouta L (2019) Mobbing Syndrome among Nursing Staff in Pediatric Departments of a Hospital in Thessaloniki. International Journal of Medical Science and Clinical Invention 6(2): 4345-4353.

3. Bakker AB, Killmer C H, Siegriest J, Schaufeli WB (2000) Effort reward imbalance and burnout among nurses. J Adv Nurs 31: 884-891.

4. Tachtsoglou K, Lera M, Iliadis C, Frantzana A, Kourkouta L (2018) Occupational Burnout of Healthcare Professionals in Hospital. Journal of Healthcare Communications 3(3): 38. 
5. Maslach C (1982) Burnout: the cost of caring. New Jersey: Prentice Hall Inc, CA.

6. Titomichlaki M, Kafetzakis B, Karamalaki M, Chaniotakis A (2010) Fatigue of health professionals. Medical Chronicles 29: 242-248.

7. (2011) Health at a Glance 2011 OECD Indicators.

8. Kandri Th, Kalemis G, Moschos N (2004) The Phenomenon of the Occupational Burnout Syndrome in the Medical Staff of the Trauma Unit of the General Hospital Of Nikaia 43(1): 116-125.

9. Koinis A, Saridi M (2013) Mobbing at the Workplace. Effects of mobbing in health. Hellenic Journal of Nursing Science 6(1): 36-48.

10. Patrinos D, Anastasiou A (2013) Human Resources Management and Development. Papazisis Publications, Greece.

11. Polyzos N (2014) Management and Organization of Health Services. Kritiki Publications, Greece.

12. Koutelekos I, Polykandriotis M (2007) Occupational Burnout Syndrome. The Step of Asclepius 6(1): 3-7.

13. Stavropoulou A, Papadaki E, Fylaki A, Kampa E (2010) Occupational Burnout Syndrome: Understanding and Early Recognition of Syndrome by Nursing Staff in Public and Private Hospitals. The Step of Asclepius 9(3): 359-374.

14. Bourantas D (2005) Leadership, the path of sustained success. Kritiki Publications, Greece.

15. Frantzana A, Charalambous M (2019) Hospital Hygiene and Safety. Am J Biomed Sci \& Res 2(5): 172-176.

16. Charalambous M, Konstantinos M, Talias MA (2017) Data on motivationa factors of the medical and nursing staff of a Greek Public Regional General Hospital during the economic crisis. Data Brief 11: 371-381.

17. Markovitch Y (2002) Human factor management: motivation power University Studio Press, Greece.

18. Markovits Y, Davis AJ, Fay D, Van Dick R (2010) The link between job satisfaction and organizational commitment-Differences between public and private sector employees. Inter Publ Manage J 13(2): 177-196.

19. Kevin Cashman (2005) AACN Standards for Establishing and Maintaining Healthy Work Environment: A journey to excellence, ( $2^{\text {nd }}$ edn), CA, USA, p. 1-44.

20. Luthans F (1992) Organizational behavior, New York: McGraw-Hill Book Co Management in Public Service: Paradoxes, Processes and Problems, Sage Publications.

21. Manolopoulos D (2009) An evaluation of employee motivation in the extended public sector in Greece. Employee Relations, University Press Studio Press, Greece.
22. Sullivan EJ, Decker PJ (2009) Effective Leadership and Management in Health Services. Giourdas Publications, Greece.

23. Lambrakis A (2016) Bass Leadership Multifactor Model: Public Sector Research Implementation. Astrolavos 25(6): 70-85.

24. Marquis B, Huston C (2011) Administration and Leadership. Theory and application in Nursing Services. Medical Publishing Hare, Greece.

25. Rosales RA, Labrague LJ, Rosales GL (2013) Nurses' job satisfaction and burnout: Is there a connection?. International Journal of Advanced Nursing Studies 2(1): 1-10.

26. Psilopanagioti A, Anagnostopoulos F, Mourtou E, Niakas D (2012) Emotional intelligence, emotional labor, and job satisfaction among physicians in Greece. BMC Health Serv Res 12: 463.

27. Toode K, Routasalo P, Helminen M, Suominen T (2014) Hospital nurses individual priorities, internal psychological states and work motivation. International Council of Nurses 61(3): 361-370.

28. Makrygiorgakis M (2001) The Human side of Management. Papazisis Publications, Greece.

29. Joseph ML, Huber DL (2015) Clinical leadership development and education for nurses: prospects and opportunities. Journal of Healthcare Leadership 7: 55-64.

30. Dikaios K, Koutouzis M, Polyzos N, Sigalas I, Chletsos M (1999) Basic principles of management of health services. Edition.

31. Thanasas I, Charalambous M (2016) Principles of Contemporary Public Hospital in Greece. Surgical Chronicles 21(2): 158-170.

32. Robbins S, Decenzo D, Coulter M (2012) Business Administration, Principles and Applications. Kritiki Publications, Greece.

33. Tsaloglidou A, Koukourikos K, Pantelidou P, Kourkouta L (2015) Burnout of Nurses. International Congress Sanitas Magisterium Istanbul, Turkey, pp. 112-113.

34. Ledford G (2014) The changing landscape of employee rewards: Observations and prescriptions. Organizational Dynamics 43(3): 168179.

35. Papathanasiou IV, Kleisiaris CF, Tsaras K, Fradelos EC, Kourkouta L (2015) General Satisfaction among Healthcare Workers: Differences between Employees in Medical and Mental Health Sector. Mater Sociomed 27(4): 225-228.

36. Nikolaou E, Dimitriou P, Kleisiaris C, Kourkouta L (2014) Study of the professional boredom syndrome in the health sector. ProgramAbstracts, 1st Nursing Mental Health one-day conference of Mental Health Center of Mamatseio Kozani Hospital. 